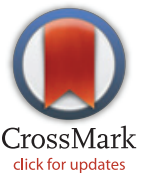

click for updates
RESEARCH ARTICLE

\section{Acute Effects of Particulate Air Pollution on the Incidence of Coronary Heart Disease in Shanghai, China}

\author{
Xiaofang Ye ${ }^{1,2 *}$, Li Peng ${ }^{2}$, Haidong Kan ${ }^{3}$, Weibing Wang ${ }^{3,4}$, Fuhai Geng ${ }^{2}$, Zhe $\mathrm{Mu}^{2}$, \\ Ji Zhou ${ }^{2}$, Dandan Yang ${ }^{2}$
}

1 Department of Environment Health, School of Public Health, Fudan University, Shanghai, China, 2 Shanghai Key Laboratory of Meteorology and Health, Shanghai Meteorological Service, Shanghai, China, 3 School of Public Health and Key Laboratory of Public Health Safety (Ministry of Education), Fudan University, Shanghai, China, 4 Fudan Tyndall Centre, Shanghai, China

* tideye@163.com

\section{Abstract}

\section{G openaccess}

Citation: Ye X, Peng L, Kan H, Wang W, Geng F, Mu Z, et al. (2016) Acute Effects of Particulate Air Pollution on the Incidence of Coronary Heart Disease in Shanghai, China. PLoS ONE 11(3): e0151119. doi:10.1371/journal.pone.0151119

Editor: Stephania Ann Cormier, University of Tennessee Health Science Center, UNITED STATES

Received: September 29, 2015

Accepted: February 22, 2016

Published: March 4, 2016

Copyright: $\odot 2016$ Ye et al. This is an open access article distributed under the terms of the Creative Commons Attribution License, which permits unrestricted use, distribution, and reproduction in any medium, provided the original author and source are credited.

Data Availability Statement: Air pollution data used in this study are obtained from Shanghai Environmental Monitoring Center, which could also be accessed from the website (http://www.envir.gov. cn/airnews/index.asp) according to individual API (Air Pollution Index) of each pollutant. Daily meteorological data are freely available. The health data we used for this study are not publicly available. With a proper ethics approval, the data can be obtained by contacting Ms. Airong Wang (Email: war71@126.com) at Shanghai Health Insurance Bureau, which provides anonymized and de-identified health administrative data to researchers.

\section{Introduction}

Evidence based on ecological studies in China suggests that short-term exposure to particulate matter (PM) is associated with cardiovascular mortality. However, there is less evidence of PM-related morbidity for coronary heart disease (CHD) in China. This study aims to investigate the relationship between acute PM exposure and $\mathrm{CHD}$ incidence in people aged above 40 in Shanghai.

\section{Methods}

Daily CHD events during 2005-2012 were identified from outpatient and emergency department visits. Daily average concentrations for particulate matter with aerodynamic diameter less than 10 microns $\left(\mathrm{PM}_{10}\right)$ were collected over the 8-year period. Particulate matter with aerodynamic diameter less than 2.5 microns $\left(\mathrm{PM}_{2.5}\right)$ were measured from 2009 to 2012. Analyses were performed using quasi-poisson regression models adjusting for confounders, including long-term trend, seasonality, day of the week, public holiday and meteorological factors. The effects were also examined by gender and age group (41-65 years, and $>65$ years).

\section{Results}

There were $619928 \mathrm{CHD}$ outpatient and emergency department visits. The average concentrations of $\mathrm{PM}_{10}$ and $\mathrm{PM}_{2.5}$ were $81.7 \mu \mathrm{g} / \mathrm{m}^{3}$ and $38.6 \mu \mathrm{g} / \mathrm{m}^{3}$, respectively. Elevated exposure to $\mathrm{PM}_{10}$ and $\mathrm{PM}_{2.5}$ was related with increased risk of $\mathrm{CHD}$ outpatients and emergency department visits in a short time course. A $10 \mu \mathrm{g} / \mathrm{m}^{3}$ increase in the 2-day $\mathrm{PM}_{10}$ and $\mathrm{PM}_{2.5}$ was associated with increase of $0.23 \%(95 \% \mathrm{Cl}: 0.12 \%, 0.34 \%)$ and $0.74 \%(95 \% \mathrm{Cl}$ : $0.44 \%, 1.04 \%$ ) in CHD morbidity, respectively. The associations appeared to be more evident in the male and the elderly. 
Funding: This study was funded by the Scientific Research Program Science and Technology Commission of Shanghai Municipality (Grant No. 12dz1202600) and the Global Environment Change Research of Fudan University Tyndall Centre (Grant No. EZH1829007/003). The funders had no role in study design, data collection and analysis, decision to publish, or preparation of the manuscript.

Competing Interests: The authors have declared that no competing interests exist.

\section{Conclusion}

Short-term exposure to high levels of $\mathrm{PM}_{10}$ and $\mathrm{PM}_{2.5}$ was associated with increased risk of CHD outpatient and emergency department visits. Season, gender and age were effect modifiers of their association.

\section{Introduction}

Coronary heart disease (CHD), also called ischemic heart disease, could lead to sudden onset of lifethreatening acute events and is associated with significant morbidity [1,2]. It is the leading cause of death in the world according to the 2010 Global Burden of Disease Study [3]. In China, the CHD prevalence has been increasing during the decades. It has reported that age-standardized mortality rate of CHD in Chinese population increased from 62.52 per 100000 people in 1990 to 77.89 per 100000 people in 2010, which meant there were over 900 thousand death due to CHD in 2010 [4]. In recent years, evidence of the increased risk of $\mathrm{CHD}$ development and exacerbation after exposure to ambient particulate matter (PM) has been provided in epidemiological studies [5-8]. Particulate air pollution is of similar importance as other well accepted triggers of myocardial infarction, one subtype of CHD, such as physical exertion when the exposure prevalence in the population is considered [7]. As PM exposure is ubiquitous for population, it has considerable public health relevance, especially in China where the particulate air pollution is much severe [9]. Although many studies have reported associations between short-term PM exposure and total cardiovascular mortality in several cities in China [10-15], there is very scarce evidence on CHD morbidity [16]. Only one study in Shanghai has evaluated the acute effects of $\mathrm{PM}_{10}$ (particulate matter less than $10 \mu \mathrm{m}$ in aerodynamic diameter) on emergency department visits due to CHD based on one hospital data [17], which requires more large-scale studies in China as there might be different effects and/or effect magnitudes from the results in developed countries with much lower level of ambient PM.

Therefore, we performed a time-series study to investigate the acute effects of ambient PM on outpatients and emergency department visits for $\mathrm{CHD}$ in people aged over 40 years in Shanghai, China.

\section{Methods}

\section{Health data}

We analyzed daily CHD morbidity data in people aged above 40 years in 2005-2012 from hospital outpatient and emergency department visits in Shanghai. Data was obtained from Shanghai Health Insurance Bureau (SHIB). SHIB is the government agency in charge of the Shanghai Health Insurance System (SHIS), which provides compulsory universal health insurance to the most permanent residents in Shanghai (the coverage rate was $89.1 \%$ in 2010) [18]. As CHD diagnosis was not recorded in the SHIS for outpatient and emergency department visits, it was inferred from the medicine prescribed in the medical record, which was used for the conventional treatment of angina pectoris and myocardial infarction (MI), such as nitrates (nitroglycerin, isosorbide dinitrate), calcium channel blockers (verapamil, diltiazem) and beta-blockers (metoprolol). Nitroglycerin has been widely used for the treatment of angina and MI. Studies have reported a reduced risk of death associated with early treatment with nitroglycerin $[19,20]$. Verapamil and diltiazem, as vasodilators, can restore coronary artery flow and myocardial perfusion efficiently [21,22]. Beta-blocker therapy has been recommended in the course of MI for patients who are not at high risk for complications. It has revealed that metoprolol is the most frequently used beta-blocker in MI patients in China [23]. Daily CHD counts were stratified by gender and age groups ( $41-65$ years, and $>65$ years). 
The Institutional Review Board at the School of Public Health, Fudan University, approved the study protocol (NO. 2012-03-0324) with a waiver of informed consent. Health information was released to us at aggregate level without any potential of identifying individual patients. There was no contact with patients for this study.

\section{Exposure data}

Daily data of air pollution included $\mathrm{PM}_{10}$, particulate matter less than $2.5 \mu \mathrm{m}$ in aerodynamic diameter $\left(\mathrm{PM}_{2.5}\right)$, sulfur dioxide $\left(\mathrm{SO}_{2}\right)$, nitrogen dioxide $\left(\mathrm{NO}_{2}\right)$ and ozone $\left(\mathrm{O}_{3}\right)$. The daily average concentrations of $\mathrm{PM}_{10}, \mathrm{SO}_{2}$ and $\mathrm{NO}_{2}$ in 2005-2012 were obtained from Shanghai Environmental Monitoring Center. As $\mathrm{PM}_{2.5}$ and $\mathrm{O}_{3}$ were not routinely monitored as the criteria pollutants in China before 2013, the daily $\mathrm{PM}_{2.5}$ data in 2009-2012 and $\mathrm{O}_{3}$ data in 2007-2012 were got alternatively from Pudong Meteorological Service and Shanghai Center of Urban Environmental Meteorology, respectively. The daily $\mathrm{O}_{3}$ was the daily maximum values of 8-h running mean. Weather data in 2005-2012 was obtained from Shanghai Meteorological Service, including daily mean temperature and relative humidity.

\section{Statistical analysis}

Health data and exposure data were linked by date for time-series analysis. As the daily counts of CHD outpatient and emergency department visits were approximately Poisson distributed, we used a Poisson regression (quali-likelihood) in generalized linear models to estimate the association between CHD morbidity and PM exposure. The moving averaged concentrations of PM on the same day and the day before (lag 01) were used to present the main results. Data was also stratified by season (defined as warm season, May-October; and cold season, November-April). We controlled for the long-term time trend with a natural cubic regression spline with 7 degrees of freedom (df) per year [24], and $3 \mathrm{df}$ per season per year for season-stratified analysis. We also controlled for day of the week and public holiday with indicator variables, and for daily temperature and relative humidity with a natural cubic spline with $4 \mathrm{df}$ for each. We then added $\mathrm{PM}_{10}$ or $\mathrm{PM}_{2.5}$ with a natural cubic spline in a single pollutant model. As the CHD risk increased monotonously with ambient PM concentration, a linear effect of PM was then assumed in the model. The model is as below:

$$
\begin{aligned}
\log E\left(Y_{t}\right)= & \text { Intercept }+n s(\text { time }, d f)+n s(\text { temperature }, 4)+n s(\text { humidity }, 4)+\text { dow }+ \text { holiday } \\
& +\alpha P M_{t-1, t}
\end{aligned}
$$

where $E\left(Y_{t}\right)$ represents the expected count of CHD morbidity on day $t, n s$ is a natural cubic spline, $\mathrm{PM}_{t-1, t}$ indicates 2-day averaged concentrations of PM on day $t$ - 1 and $t$. Besides the main results on lag 01, PM on a single day lagged from the current day (lag 0 ) to the previous 6 days (lag 1 to lag 6) were also analyzed to examine the lag structure. To test the stability of PM effects on CHD morbidity, we added one of the gaseous pollutants $\left(\mathrm{SO}_{2}, \mathrm{NO}_{2}\right.$ and $\left.\mathrm{O}_{3}\right)$ into the single pollutant model. We also performed a sensitivity analysis by varying the $\mathrm{df}$ for the time trend (from 5 to $13 \mathrm{df}$ per year) to control for seasonality in the models.

Data management and regression analysis were performed with R version 3.1.0 (The R Project for Statistical Computing, http://www.r-project.org).

\section{Results}

In this study, we examined 604944 CHD outpatient and emergency department visits in people aged above 40 years. Table 1 summarizes daily CHD morbidity, $\mathrm{PM}_{10}, \mathrm{PM}_{2.5}$, temperature and relative humidity during 2005-2012. On average, there were $207 \mathrm{CHD}$ patients visiting 
Table 1. Summary (mean \pm SD) of daily CHD outpatient and emergency department visits, PM concentrations and weather conditions in Shanghai in 2005-2012.

\begin{tabular}{|c|c|c|c|c|}
\hline & & All seasons & Cold season & Warm season \\
\hline \multicolumn{5}{|c|}{ CHD outpatient and emergency department visits (n) } \\
\hline & All & $207.0 \pm 51.1$ & $237.8 \pm 48.3$ & $176.7 \pm 32.0$ \\
\hline & Male & $92.4 \pm 24.9$ & $107.0 \pm 24.1$ & $78.0 \pm 15.5$ \\
\hline & Female & $114.6 \pm 28.5$ & $130.8 \pm 27.0$ & $98.7 \pm 19.6$ \\
\hline & 41-65years & $56.6 \pm 12.7$ & $61.9 \pm 12.7$ & $51.5 \pm 10.5$ \\
\hline & $>65$ years & $150.4 \pm 43.7$ & $175.9 \pm 42.3$ & $125.2 \pm 27.4$ \\
\hline $\mathrm{PM}_{10}\left(\mu \mathrm{g} / \mathrm{m}^{3}\right)$ & & $81.7 \pm 54.4$ & $93.8 \pm 60.1$ & $70.0 \pm 45.4$ \\
\hline $\mathrm{PM}_{2.5}\left(\mu \mathrm{g} / \mathrm{m}^{3}\right)^{\mathrm{a}}$ & & $38.6 \pm 26.7$ & $48.7 \pm 29.3$ & $28.9 \pm 19.5$ \\
\hline Temperature $\left({ }^{\circ} \mathrm{C}\right)$ & & $17.4 \pm 9.1$ & $9.7 \pm 5.6$ & $25.0 \pm 4.3$ \\
\hline Relative Humidity (\%) & & $69.5 \pm 12.3$ & $67.9 \pm 13.8$ & $71.1 \pm 10.4$ \\
\hline
\end{tabular}

${ }^{\mathrm{a} P M_{2.5}}$ data was in 2009-2012.

doi:10.1371/journal.pone.0151119.t001

outpatients and emergency departments each day. Daily counts of CHD morbidity in the cold season were larger than those in the warm season. There were more female patients in the outpatient and emergency departments. Patients older than 65 years accounted for almost three quarters of the total $\mathrm{CHD}$ morbidity. The overall mean concentrations of $\mathrm{PM}_{10}$ and $\mathrm{PM}_{2.5}$ were $81.7 \mu \mathrm{g} / \mathrm{m}^{3}$ and $38.6 \mu \mathrm{g} / \mathrm{m}^{3}$, respectively. The concentrations of $\mathrm{PM}_{10}$ and $\mathrm{PM}_{2.5}$ were both higher in the cold season than those in the warm season. The mean temperature was $25.0^{\circ} \mathrm{C}$ in the warm season and $9.7^{\circ} \mathrm{C}$ in the cold season.

Fig 1 shows the relationship between PM at lag 01 and the total CHD morbidity. In general, CHD morbidity were positively related with both $\mathrm{PM}_{2.5}$ and $\mathrm{PM}_{10}$. An approximate linear

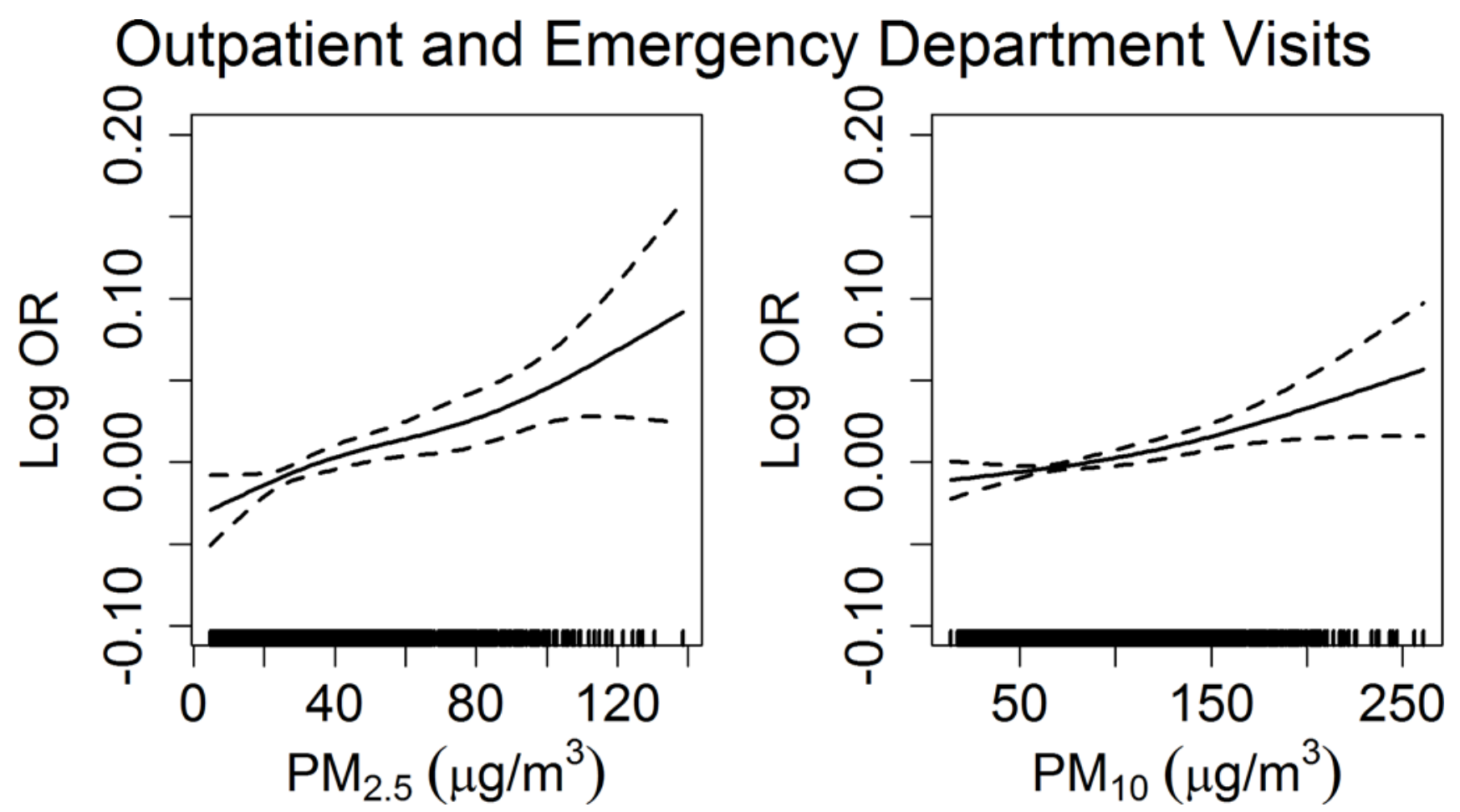

Fig 1. Smoothing plots of $\mathrm{PM}_{2.5}$ (left) and $\mathrm{PM}_{10}$ (right) against $\mathrm{CHD}$ outpatient and emergency department visits. $X$-axis is the $P M$ concentrations at lag 01 . The solid lines indicate the estimated mean percentage of change in daily outpatient and emergency department visits for CHD, and the dotted lines represent twice the standard error.

doi:10.1371/journal.pone.0151119.g001 
Table 2. Estimated percent difference in CHD outpatient and emergency department visits $(95 \% \mathrm{Cl})$ in association with a $10 \mu \mathrm{g} / \mathrm{m}^{3}$ increase in $P M_{2.5}$ and $P M_{10}$ at lag 01 by season, gender and age group.

\begin{tabular}{|c|c|c|c|c|c|c|}
\hline \multirow[t]{2}{*}{ Group } & \multicolumn{2}{|c|}{ All seasons } & \multicolumn{2}{|c|}{ Warm season } & \multicolumn{2}{|c|}{ Cold season } \\
\hline & $\mathrm{PM}_{2.5}$ & $\mathrm{PM}_{10}$ & $\mathrm{PM}_{2.5}$ & $\mathrm{PM}_{10}$ & $\mathrm{PM}_{2.5}$ & $\mathrm{PM}_{10}$ \\
\hline All & $0.74(0.44,1.04)^{*}$ & $0.23(0.12,0.34)^{*}$ & $0.40(-0.15,0.95)$ & $0.17(-0.01,0.35)$ & $0.93(0.53,1.34)^{*}$ & $0.28(0.12,0.43)^{*}$ \\
\hline Male & $1.10(0.72,1.47)^{*}$ & $0.33(0.19,0.47)^{*}$ & $1.05(0.35,1.75)^{*}$ & $0.28(0.05,0.52)^{*}$ & $1.25(0.78,1.73)^{*}$ & $0.38(0.20,0.57)^{*}$ \\
\hline Female & $0.44(0.10,0.79)^{*}$ & $0.14(0.01,0.27)^{*}$ & $-0.13(-0.76,0.51)$ & $0.08(-0.14,0.29)$ & $0.67(0.22,1.13)^{*}$ & $0.19(0.01,0.36)^{*}$ \\
\hline 41-65years & $0.54(0.09,1.00)^{*}$ & $0.09(-0.07,0.26)$ & $-0.28(-1.04,0.49)$ & $0.01(-0.26,0.27)$ & $0.79(0.22,1.37)^{*}$ & $0.13(-0.09,0.34)$ \\
\hline >65years & $0.80(0.47,1.13)^{*}$ & $0.27(0.15,0.40)^{*}$ & $0.64(0.00,1.29)^{*}$ & $0.24(0.03,0.45)^{*}$ & $0.97(0.54,1.41)^{*}$ & $0.33(0.17,0.50) *$ \\
\hline
\end{tabular}

doi:10.1371/journal.pone.0151119.t002

effect of PM was found for CHD morbidity. CHD morbidity monotonously increased with the 2-day averaged concentrations of $\mathrm{PM}_{2.5}$ and $\mathrm{PM}_{10}$.

Table 2 presents the estimated percent of change in CHD morbidity for a $10 \mu \mathrm{g} / \mathrm{m}^{3}$ increase in 2-day averaged concentrations of $\mathrm{PM}_{2.5}$ and $\mathrm{PM}_{10}$ in different seasons. We found statistically significant associations between elevated PM exposure and increased number of CHD patients. A $10 \mu \mathrm{g} / \mathrm{m}^{3}$ increase in $\mathrm{PM}_{2.5}$ at lag 01 was associated with a $0.74 \%$ (95\% CI: $0.44 \%, 1.04 \%$ ) increase in CHD outpatient and emergency department visits, which was larger than that for $\mathrm{PM}_{10}$ with a $0.23 \%$ (95\% CI: $0.12 \%, 0.34 \%$ ) increase. There were different seasonal effects of PM on the total CHD morbidity. Significant PM effects were observed in the cold season, however, they were not statistically significant in the warm season. For instance, the estimate of the effect of $\mathrm{PM}_{2.5}$ on CHD outpatient and emergency department visits was largest in the cold season and equal to an estimated 0.93\% (95\% CI: 0.53\%, 1.34\%) increase in CHD risk per $10 \mu \mathrm{g} / \mathrm{m}^{3}$ increase in $\mathrm{PM}_{2.5}$ at lag 01 in the cold season, whereas it was nonsignificant in the warm season. Table 2 also indicates the PM effects on CHD morbidity in patients of different demographic factors. Gender and age could modify the association between PM exposure and CHD risk. The greater effect estimates were observed in men and people older than 65 years. In the cold season, there was obvious evidence of PM effects on increased risk of CHD morbidity except in people aged 41-65 years old for $\mathrm{PM}_{10}$. In the warm season, the effects of both $\mathrm{PM}_{2.5}$ and $\mathrm{PM}_{10}$ were only found in the male and the elderly.

Fig 2 shows the estimated percentage of change in CHD risk for a $10 \mu \mathrm{g} / \mathrm{m}^{3}$ increase in $\mathrm{PM}_{10}$ and $\mathrm{PM}_{2.5}$ at different lag days. Across all seasons, we found that the estimates of the effects of $\mathrm{PM}_{2.5}$ and $\mathrm{PM}_{10}$ on CHD morbidity were largest at lag 0 . There were increases of $0.63 \%$ (95\% CI: $0.38 \%, 0.88 \%)$ and $0.26 \%$ (95\% CI: $0.18 \%, 0.33 \%)$ in CHD risk for each $10 \mu \mathrm{g} /$ $\mathrm{m}^{3}$ increase in $\mathrm{PM}_{2.5}$ and $\mathrm{PM}_{10}$ on the same day, respectively. CHD morbidity was also associated with $\mathrm{PM}_{2.5}$ at lag 1 and lag 5, with $\mathrm{PM}_{10}$ from lag 2 to lag 4 .

Table 3 compares the results of single PM models with models adjusted for other gaseous pollutants. After controlling for $\mathrm{SO}_{2}, \mathrm{NO}_{2}$ or $\mathrm{O}_{3}$, the $\mathrm{PM}_{2.5}$ effects on CHD morbidity generally remained statistically significant, although the magnitude increased for $\mathrm{SO}_{2}$ and decreased for $\mathrm{NO}_{2}$. The estimates of effects of $\mathrm{PM}_{2.5}$ and $\mathrm{PM}_{10}$ changed slightly after $\mathrm{O}_{3}$ was added in the models. The $\mathrm{PM}_{10}$ effects on CHD morbidity tended to be insignificant after adjustment for $\mathrm{SO}_{2}$ and $\mathrm{NO}_{2}$. The choice of $\mathrm{df}$ for the time trend from 5 to 13 per year did not substantially affect the estimates of the effects of PM on CHD outpatient and emergency department visits (data not shown).

\section{Discussion}

Although there are many studies investigated the association between ambient PM exposure and CHD morbidity and mortality in the US, the UK and other developed countries where PM 


\section{Outpatient and Emergency Department Visits}

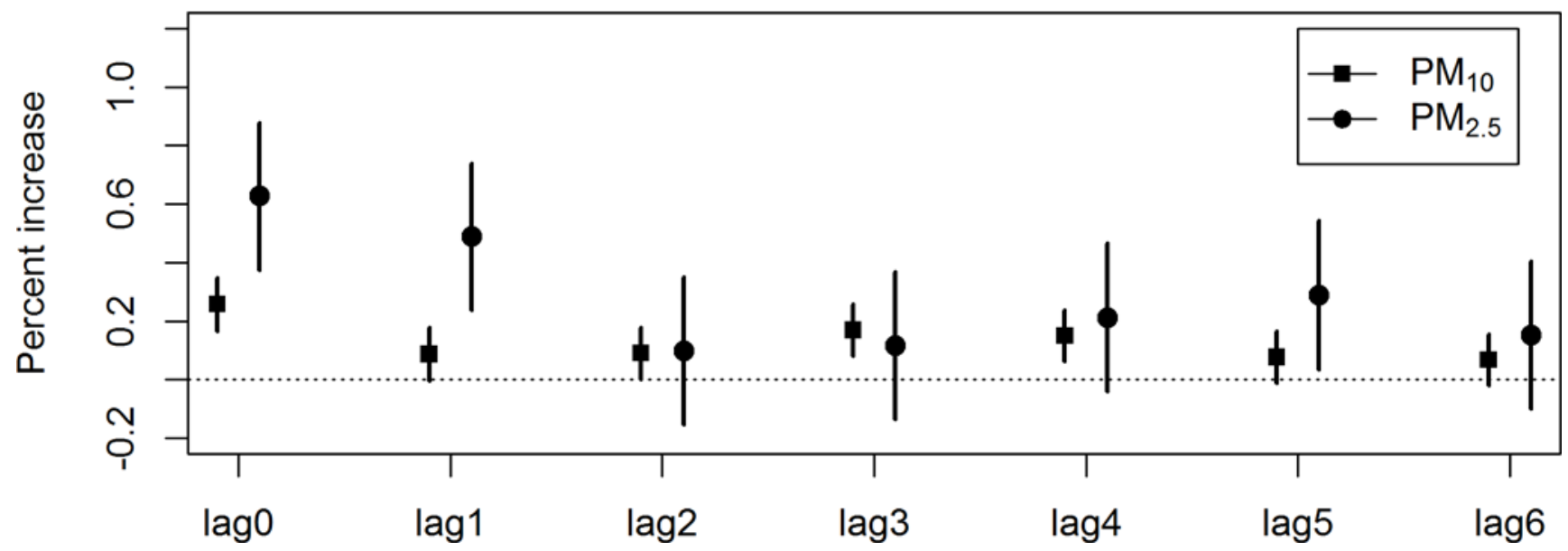

Fig 2. Estimated percent difference in CHD outpatient and emergency department visits $(95 \% \mathrm{Cl})$ in association with a $10 \mu \mathrm{g} / \mathrm{m}^{3}$ increase in $\mathrm{PM} \mathrm{I}_{10}$ and $\mathrm{PM}_{2.5}$ by lag days.

doi:10.1371/journal.pone.0151119.g002

concentration is quite low $[25,26]$, evidence is limited with regard to the effects at higher levels of particulate air pollution. This study supports significant effects of both $\mathrm{PM}_{10}$ and $\mathrm{PM}_{2.5}$ on the acute onset and exacerbation of CHD, and also provides evidence of increased CHD risk at high elevated PM. This study, to our knowledge, is one of the few studies in China to evaluate the acute effects of PM on CHD morbidity $[2,17,27,28]$.

Our results are mostly consistent with previous studies which reported significantly detrimental effects of particulate air pollution $[6,26]$. Studies in US and European cities have found high risk of CHD events due to recent PM exposure [1]. For example, Zanobetti et al [29] found an increase of $2.25 \%$ (95\%CI: $1.10 \%, 3.42 \%$ ) in MI admissions for a $10 \mu \mathrm{g} / \mathrm{m}^{3}$ increase in 2-day averaged $\mathrm{PM}_{2.5}$ concentration in 26 US communities. In our study, the effect estimate was slightly smaller, with only $0.74 \%$ (95\% CI: $0.44 \%, 1.04 \%$ ) increase in CHD outpatient and emergency department visits per $10 \mu \mathrm{g} / \mathrm{m}^{3}$ increase in $\mathrm{PM}_{2.5}$. The $\mathrm{PM}_{2.5}$ concentration was shown under $20 \mu \mathrm{g} / \mathrm{m}^{3}$ in most US communities, almost half of the level in Shanghai in our study. The different effect magnitudes may be due to pollution level and population susceptibility in different locations, which was suggested in both US and China that the exposureresponse function between cardiovascular mortality and PM exposure was relatively steep at very low levels of exposure and flattened out at higher exposure levels [30,31].

Two types of hospital visits, outpatient and emergency department visits, were combined together to be analyzed in this study. Their ratio was about $10 \%$. Outpatient visits are usually

Table 3. Estimated percent difference in CHD outpatient and emergency department visits $(95 \% \mathrm{Cl})$ in association with a $10 \mu \mathrm{g} / \mathrm{m}^{3}$ increase in $\mathrm{PM}_{2.5}$ and $\mathrm{PM}_{10}$ with or without adjustment for gaseous pollutants.

\begin{tabular}{lcc}
\hline Adjustment & $\mathbf{P M}_{2.5}$ & $\mathbf{P M}_{\mathbf{1 0}}$ \\
\hline Without adjustment & $\mathbf{0 . 7 4}\left(\mathbf{0 . 4 4 , 1 . 0 4 ) ^ { * }}\right.$ & $\mathbf{0 . 2 3}(\mathbf{0 . 1 2}, \mathbf{0 . 3 4})^{*}$ \\
Adjusted for $\mathrm{SO}_{2}$ & $\mathbf{1 . 0 9 ( 0 . 6 3 , 1 . 5 5 ) ^ { * }}$ & $0.07(-0.07,0.21)$ \\
Adjusted for $\mathrm{NO}_{2}$ & $\mathbf{0 . 5 9 ( 0 . 1 6 , 1 . 0 2 ) ^ { * }}$ & $-0.04(-0.18,0.10)$ \\
Adjusted for $\mathrm{O}_{3}$ & $\mathbf{0 . 7 3 ( 0 . 4 2 , 1 . 0 3 ) ^ { * }}$ & $\mathbf{0 . 2 3}(\mathbf{0 . 1 0}, \mathbf{0 . 3 5})^{*}$ \\
\hline${ }^{*} p<0.05$. & & \\
\hline
\end{tabular}

doi:10.1371/journal.pone.0151119.t003 
not regarded as a good outcome in epidemiological studies of acute effects of air pollution in the US and Europe, where they are scheduled by appointment. However, situation is different in China. Outpatient visits are unscheduled as emergency department visits, and are first-come first-served. Patients could receive timely medical service in either outpatient or emergency departments. Therefore, the combined records of outpatient and emergency department visits in our study may have the potential to reflect the true morbidity information and offer opportunity to evaluate the acute effects of particulate air pollution.

An immediate impact on CHD of increased level of both $\mathrm{PM}_{2.5}$ and $\mathrm{PM}_{10}$ was found in the concurrent day (lag 0 ) and the previous day (lag 1), which was consistent with studies conducted in other locations showing a short time course [32,33]. We also observed the largest increase in CHD morbidity at lag 0 for PM exposure, which suggested an even shorter than daily timescale for PM effect on CHD incidence. Although it is impossible to assess the association on sub-daily level in this study, some studies have documented increased risk in hours after exposure to elevated PM [34,35].

Analyses by season indicated that effect estimates were higher in the cold season. A few studies found the modification of season or temperature on the PM-related effects on cardiovascular morbidity and mortality [36,37]. Our findings of a stronger association between particulate air pollution and cardiovascular risk in the cold season were consistent with previous studies in Shanghai $[17,38]$. The enhanced effects on ischemic heart disease in cool and dry weather were also indicated in Hong Kong [39]. One possible explanation is related to low temperature and increased blood pressure and viscosity in the cold season, which could be important causal factors in increasing winter morbidity and mortality due to heart attacks and strokes $[40,41]$. Another possible reason is the varying source and composition of PM in different seasons. In Shanghai, the prevailing wind direction is northwestern to northern in the cold season and southeast to east in the warm season, respectively [42]. The northern air flow transports high concentration $\mathrm{PM}_{2.5}$ emitted from coal burning for residential heating and biomass burning in the northern China in the cold season, while the eastern air flow which comes from the East China Sea carries clean air in summer [43]. For example, BC aerosol mass of non-local sources transported to Shanghai was highest in winter [44].

Stronger effects were observed in the elderly and male patients in the study. It is easy to understand the elderly are more vulnerable to particulate air pollution. Gender is usually treated as an effect modifier in air pollution epidemiology [45]. However results of previous studies on gender-specific effects of PM on CHD were conflicting [17,46]. Particulate air pollution showed higher CHD risk in the male in this study, which may be related to high exposure level of air pollution and tobacco smoking in men than women in China [47].

It is a challenge to elucidate the underling mechanisms of the PM effects on CHD, however, several possible mechanisms have been suggested in experimental studies and epidemiological studies. One potential mechanism is systemic inflammation, which is closely associated with cardiovascular diseases [48]. It has been shown that levels of inflammation markers such as high-sensitivity C-reactive protein increased significantly after exposure to particulate air pollution [49,50]. Increase in oxidative stress [51], endothelial dysfunction [52], blood viscosity $[53,54]$ due to particulate exposure were also reported. They can accelerate the progression of atherosclerosis, cause the plaque instable, promote the formation of thrombosis, and increase the susceptibility to CHD. The other one potential mechanism is the impaired cardiac autonomic system as a result of particulate exposure. A reduced heart rate variability is usually treated as a marker of cardiac autonomic dysfunction. Studies on the association between short-term exposure to particulate air pollution and heart rate variability have supported an inverse relationship [55]. 
There are several limitations in this study. Firstly, the CHD records in outpatient and emergency department visits were not diagnosed according to ICD-10 but on medication prescription, which made misclassification with other cardiovascular diseases unavoidable, although the medicine was ascertained by several clinicians in hospitals. Hypertension could be included partly in this study as beta-blockers and calcium channel blockers have the effect of reducing blood pressure. Secondly, we used one monitoring data of $\mathrm{PM}_{2.5}$ for only 4 years, different from the city-wide $\mathrm{PM}_{10}$ data for 8 years. $\mathrm{PM}_{2.5}$ data from one monitoring station may has measurement error and introduce bias to our results.

In summary, in this time-series study coving large amount of CHD outpatient and emergency department visits in Shanghai during 2005-2012, we found that particulate air pollution $\left(\mathrm{PM}_{10}\right.$ and $\left.\mathrm{PM}_{2.5}\right)$ was statistically significantly associated with increased $\mathrm{CHD}$ risk. Furthermore, the PM effects were higher in the cold season, the male and those over 65 years. These findings provide new evidence of high PM level on CHD incidence and may suggest further investigation on specific cardiovascular diseases in China.

\section{Acknowledgments}

The authors thank the Shanghai Health Insurance Bureau for their contribution of health data clearance and management to this study, and thank Dr. Hui Zhang from Shanghai Tenth People's Hospital of Tongji University for her professional suggestion on the health data management.

\section{Author Contributions}

Conceived and designed the experiments: XY HK FG. Performed the experiments: XY LP. Analyzed the data: XY ZM. Contributed reagents/materials/analysis tools: XY LP WW JZ DY. Wrote the paper: XY HK.

\section{References}

1. Brook RD, Rajagopalan S, Pope CA 3rd, Brook JR, Bhatnagar A, Diez-Roux AV, et al. Particulate matter air pollution and cardiovascular disease: An update to the scientific statement from the American Heart Association. Circulation. 2010 Jun 1; 121(21):2331-78. PMID: 20458016. doi: 10.1161/CIR. 0b013e3181dbece1

2. R384 Xie W, Li G, Zhao D, Xie X, Wei Z, Wang W, et al. Relationship between fine particulate air pollution and ischaemic heart disease morbidity and mortality. Heart (British Cardiac Society). 2015 Feb; 101(4):257-63. PMID: 25341536.

3. Lozano R, Naghavi M, Foreman K, Lim S, Shibuya K, Aboyans V, et al. Global and regional mortality from 235 causes of death for 20 age groups in 1990 and 2010: a systematic analysis for the Global Burden of Disease Study 2010. Lancet. 2012 Dec 15; 380(9859):2095-128. PMID: 23245604. doi: 10. 1016/S0140-6736(12)61728-0

4. Liu J, Liu Y, Wang L, Yin P, Liu S, You J, et al. [The disease burden of cardiovascular and circulatory diseases in China, 1990 and 2010]. Chi J Prev Med. 2015; 49(4):315-20. PMID: 26081541. Chinese.

5. Wolf K, Schneider A, Breitner S, Meisinger C, Heier M, Cyrys J, et al. Associations between short-term exposure to particulate matter and ultrafine particles and myocardial infarction in Augsburg, Germany. Int J Hyg Environ Health. 2015 May 11; 218(6):535-42. PMID: 26013401. doi: 10.1016/j.ijheh.2015.05. 002

6. Mustafic H, Jabre P, Caussin C, Murad MH, Escolano S, Tafflet M, et al. Main air pollutants and myocardial infarction: a systematic review and meta-analysis. JAMA. 2012 Feb 15; 307(7):713-21. PMID: 22337682. doi: 10.1001/jama.2012.126

7. Nawrot TS, Perez L, Kunzli N, Munters E, Nemery B. Public health importance of triggers of myocardial infarction: a comparative risk assessment. Lancet. 2011 Feb 26; 377(9767):732-40. PMID: 21353301. doi: 10.1016/S0140-6736(10)62296-9

8. Martinelli N, Olivieri O, Girelli D. Air particulate matter and cardiovascular disease: a narrative review. Eur J Intern Med. 2013 Jun; 24(4):295-302. PMID: 23647842. doi: 10.1016/j.ejim.2013.04.001 
9. Ma Z, Hu X, Sayer AM, Levy R, Zhang Q, Xue Y, et al. Satellite-based spatiotemporal trends in PM2.5 concentrations: China, 2004-2013. Environ Health Perspect. 2015 Jul 24. PMID: 26220256.

10. $\mathrm{Cao} J, \mathrm{Xu} \mathrm{H}, \mathrm{Xu} \mathrm{Q}, \mathrm{Chen} \mathrm{B}, \mathrm{Kan} \mathrm{H}$. Fine particulate matter constituents and cardiopulmonary mortality in a heavily polluted Chinese city. Environ Health Perspect. 2012 Mar; 120(3):373-8. PMID: 22389181. Pubmed Central PMCID: PMC3295342. doi: 10.1289/ehp.1103671

11. Chen R, Pan G, Kan H, Tan J, Song W, Wu Z, et al. Ambient air pollution and daily mortality in Anshan, China: a time-stratified case-crossover analysis. Sci Total Environ. 2010 Nov 15; 408(24):6086-91. PMID: 20889186. doi: 10.1016/j.scitotenv.2010.09.018

12. Guo Y, Barnett AG, Zhang Y, Tong S, Yu W, Pan X. The short-term effect of air pollution on cardiovascular mortality in Tianjin, China: comparison of time series and case-crossover analyses. Sci Total Environ. 2010 Dec 15; 409(2):300-6. PMID: 21055792. doi: 10.1016/j.scitotenv.2010.10.013

13. Zhang $P$, Dong $G$, Sun $B$, Zhang L, Chen $X$, Ma N, et al. Long-term exposure to ambient air pollution and mortality due to cardiovascular disease and cerebrovascular disease in Shenyang, China. PLoS One. 2011; 6(6):e20827. PMID: 21695220. Pubmed Central PMCID: PMC3112212. doi: 10.1371/ journal.pone.0020827

14. Breitner S, Liu L, Cyrys J, Bruske I, Franck U, Schlink U, et al. Sub-micrometer particulate air pollution and cardiovascular mortality in Beijing, China. Sci Total Environ. 2011 Nov 15; 409(24):5196-204. PMID: 21937089. doi: 10.1016/j.scitotenv.2011.08.023

15. Zhang Y, Guo Y, Li G, Zhou J, Jin X, Wang W, et al. The spatial characteristics of ambient particulate matter and daily mortality in the urban area of Beijing, China. Sci Total Environ. 2012 Oct 1; 435436:14-20. PMID: 22846759. doi: 10.1016/j.scitotenv.2012.06.092

16. Lu F, Xu D, Cheng Y, Dong S, Guo C, Jiang X, et al. Systematic review and meta-analysis of the adverse health effects of ambient PM2.5 and PM10 pollution in the Chinese population. Environ Res. 2015 Jan; 136:196-204. PMID: 25460637. doi: 10.1016/j.envres.2014.06.029

17. Xie J, He M, Zhu W. Acute effects of outdoor air pollution on emergency department visits due to five clinical subtypes of coronary heart diseases in Shanghai, China. J Epidemiol. 2014; 24(6):452-9. PMID: 24998952. Pubmed Central PMCID: PMC4213219.

18. Shanghai Statistical Yearbook 2012: China Statistics Press; 2012.

19. Strandmark R, Herlitz J, Axelsson C, Claesson A, Bremer A, Karlsson T, et al. Determinants of pre-hospital pharmacological intervention and its association with outcome in acute myocardial infarction. Scand J Trauma Resusc Emerg Med. 2015; 23(1):105. PMID: 26626732. Pubmed Central PMCID: PMC4665872.

20. Perez MI, Musini VM, Wright JM. Effect of early treatment with anti-hypertensive drugs on short and long-term mortality in patients with an acute cardiovascular event. Cochrane Database Syst Rev. 2009 (4: ):CD006743. PMID: 19821384. doi: 10.1002/14651858.CD006743.pub2

21. Wang L, Cheng Z, Gu Y, Peng D. Short-term effects of verapamil and diltiazem in the treatment of no reflow phenomenon: a meta-analysis of randomized controlled trials. Biomed Res Int. 2015; 2015:382086. PMID: 26504804. Pubmed Central PMCID: PMC4609355. doi: 10.1155/2015/382086

22. Huang D, Qian J, Ge L, Jin X, Jin H, Ma J, et al. REstoration of COronary flow in patients with no-reflow after primary coronary interVEntion of acute myocaRdial infarction (RECOVER). Am Heart J. 2012 Sep; 164(3):394-401. PMID: 22980307. doi: 10.1016/j.ahj.2012.06.015

23. Zhang H, Masoudi FA, Li J, Wang Q, Li X, Spertus JA, et al. National assessment of early beta-blocker therapy in patients with acute myocardial infarction in China, 2001-2011: The China Patient-centered Evaluative Assessment of Cardiac Events (PEACE)-Retrospective AMI Study. Am Heart J. 2015 Sep; 170(3):506-15 e1. PMID: 26385034. doi: 10.1016/j.ahj.2015.05.012

24. Wang X, Chen R, Meng X, Geng F, Wang C, Kan H. Associations between fine particle, coarse particle, black carbon and hospital visits in a Chinese city. Sci Total Environ. 2013 Apr 29; 458-460C:1-6. PMID: 23639905.

25. Milojevic A, Wilkinson P, Armstrong B, Bhaskaran K, Smeeth L, Hajat S. Short-term effects of air pollution on a range of cardiovascular events in England and Wales: case-crossover analysis of the MINAP database, hospital admissions and mortality. Heart. 2014 Jul; 100(14):1093-8. PMID: 24952943. Pubmed Central PMCID: PMC4078678. doi: 10.1136/heartjnl-2013-304963

26. Dominici F, Peng RD, Bell ML, Pham L, McDermott A, Zeger SL, et al. Fine particulate air pollution and hospital admission for cardiovascular and respiratory diseases. JAMA. 2006 Mar 8; 295(10):1127-34. PMID: 16522832. Pubmed Central PMCID: PMC3543154.

27. Pun VC, Yu IT, Ho KF, Qiu H, Sun Z, Tian L. Differential effects of source-specific particulate matter on emergency hospitalizations for ischemic heart disease in Hong Kong. Environ Health Perspect. 2014 Apr; 122(4):391-6. PMID: 24509062. Pubmed Central PMCID: PMC3984224. doi: 10.1289/ehp. 1307213 
28. Yu IT, Qiu H, Wang X, Tian L, Tse LA. Synergy between particles and nitrogen dioxide on emergency hospital admissions for cardiac diseases in Hong Kong. Int J Cardiol. 2013 Oct 3; 168(3):2831-6. PMID: 23608392. doi: 10.1016/j.ijcard.2013.03.082

29. Zanobetti A, Franklin M, Koutrakis $\mathrm{P}$, Schwartz J. Fine particulate air pollution and its components in association with cause-specific emergency admissions. Environ Health. 2009; 8:58. PMID: 20025755. Pubmed Central PMCID: PMC2807856. doi: 10.1186/1476-069X-8-58

30. Pope CA 3rd, Burnett RT, Krewski D, Jerrett M, Shi Y, Calle EE, et al. Cardiovascular mortality and exposure to airborne fine particulate matter and cigarette smoke: shape of the exposure-response relationship. Circulation. 2009 Sep 15; 120(11):941-8. PMID: 19720932. doi: 10.1161/ CIRCULATIONAHA.109.857888

31. Chen R, Kan H, Chen B, Huang W, Bai Z, Song G, et al. Association of particulate air pollution with daily mortality: the China Air Pollution and Health Effects Study. Am J Epidemiol. 2012 Jun 1; 175 (11):1173-81. PMID: 22510278. doi: 10.1093/aje/kwr425

32. Belleudi V, Faustini A, Stafoggia M, Cattani G, Marconi A, Perucci CA, et al. Impact of fine and ultrafine particles on emergency hospital admissions for cardiac and respiratory diseases. Epidemiology. 2010 May; 21(3):414-23. PMID: 20386174. doi: 10.1097/EDE.0b013e3181d5c021

33. Nuvolone D, Balzi D, Chini M, Scala D, Giovannini F, Barchielli A. Short-term association between ambient air pollution and risk of hospitalization for acute myocardial infarction: results of the cardiovascular risk and air pollution in Tuscany (RISCAT) study. Am J Epidemiol. 2011 Jul 1; 174(1):63-71. PMID: 21597098. doi: 10.1093/aje/kwr046

34. Peters A, Dockery DW, Muller JE, Mittleman MA. Increased particulate air pollution and the triggering of myocardial infarction. Circulation. 2001 Jun 12; 103(23):2810-5. PMID: 11401937.

35. Bhaskaran $\mathrm{K}$, Hajat $\mathrm{S}$, Armstrong $\mathrm{B}$, Haines A, Herrett $\mathrm{E}$, Wilkinson $\mathrm{P}$, et al. The effects of hourly differences in air pollution on the risk of myocardial infarction: case crossover analysis of the MINAP database. BMJ. 2011; 343:d5531. PMID: 21933824. Pubmed Central PMCID: PMC3176903. doi: 10.1136/ bmj.d5531

36. Dai L, Zanobetti A, Koutrakis P, Schwartz JD. Associations of fine particulate matter species with mortality in the United States: a multicity time-series analysis. Environ Health Perspect. 2014 Aug; 122 (8):837-42. PMID: 24800826. Pubmed Central PMCID: PMC4123030. doi: 10.1289/ehp.1307568

37. Nawrot TS, Torfs R, Fierens F, De Henauw S, Hoet PH, Van Kersschaever G, et al. Stronger associations between daily mortality and fine particulate air pollution in summer than in winter: evidence from a heavily polluted region in western Europe. J Epidemiol Community Health. 2007 Feb; 61(2):146-9. PMID: 17234874. Pubmed Central PMCID: PMC2465652.

38. Kan H, London SJ, Chen G, Zhang Y, Song G, Zhao N, et al. Season, sex, age, and education as modifiers of the effects of outdoor air pollution on daily mortality in Shanghai, China: The Public Health and Air Pollution in Asia (PAPA) Study. Environ Health Perspect. 2008 Sep; 116(9):1183-8. PMID: 18795161. Pubmed Central PMCID: PMC2535620. doi: 10.1289/ehp.10851

39. Qiu H, Yu IT, Wang X, Tian L, Tse LA, Wong TW. Cool and dry weather enhances the effects of air pollution on emergency IHD hospital admissions. Int J Cardiol. 2013 Sep 20; 168(1):500-5. PMID: 23079091. doi: 10.1016/j.ijcard.2012.09.199

40. Kyobutungi C, Grau A, Stieglbauer G, Becher H. Absolute temperature, temperature changes and stroke risk: a case-crossover study. Eur J Epidemiol. 2005; 20(8):693-8. PMID: 16151883.

41. Hoffmann B, Luttmann-Gibson H, Cohen A, Zanobetti A, de Souza C, Foley C, et al. Opposing effects of particle pollution, ozone, and ambient temperature on arterial blood pressure. Environ Health Perspect. 2012 Feb; 120(2):241-6. PMID: 22020729. Pubmed Central PMCID: 3279434. doi: 10.1289/ ehp.1103647

42. Li M, Huang X, Zhu L, Li J, Song Y, Cai X, et al. Analysis of the transport pathways and potential sources of PM10 in Shanghai based on three methods. Sci Total Environ. 2012 Jan 1; 414:525-34. PMID: 22119031. doi: 10.1016/j.scitotenv.2011.10.054

43. Zhao M, Huang Z, Qiao T, Zhang Y, Xiu G, Yu J. Chemical characterization, the transport pathways and potential sources of PM2.5 in Shanghai: Seasonal variations. Atmos Res. 2015; 158-159:66-78.

44. Wang $\mathrm{H}$, Kang $\mathrm{Y}, \mathrm{He} \mathrm{Q}, \mathrm{Chen} \mathrm{Y}$. Transport of black carbon aerosols from non-local sources: A case study in Shanghai. Particuology. 2015; 20:89-93.

45. Clougherty JE. A growing role for gender analysis in air pollution epidemiology. Environ Health Perspect. 2010 Feb; 118(2):167-76. PMID: 20123621. Pubmed Central PMCID: PMC2831913. doi: 10 1289/ehp.0900994

46. Zanobetti A, Schwartz J. The effect of particulate air pollution on emergency admissions for myocardial infarction: a multicity case-crossover analysis. Environ Health Perspect. 2005 Aug; 113(8):978-82. PMID: 16079066. Pubmed Central PMCID: PMC1280336. 
47. Wang R, Zhu L, Yan W, Zeng G, Michael E. The influence of estimated retail tobacco sale price increase on smokers' smoking habit in Jiangxi province, China: a cross-sectional study. Tob Induc Dis. 2015; 13(1):25. PMID: 26300716. Pubmed Central PMCID: PMC4545555. doi: 10.1186/s12971-0150043-x

48. Ridker PM, Morrow DA. C-reactive protein, inflammation, and coronary risk. Cardiology clinics. 2003 Aug; 21(3):315-25. PMID: 14621448.

49. Ruckerl R, Greven $S$, Ljungman $P$, Aalto $P$, Antoniades $C$, Bellander T, et al. Air pollution and inflammation (interleukin-6, C-reactive protein, fibrinogen) in myocardial infarction survivors. Environ Health Perspect. 2007 Jul; 115(7):1072-80. PMID: 17637925. Pubmed Central PMCID: PMC1913563.

50. Zhao J, Gao Z, Tian Z, Xie Y, Xin F, Jiang R, et al. The biological effects of individual-level PM2.5 exposure on systemic immunity and inflammatory response in traffic policemen. Occup Environ Med. 2013 Jan 15. PMID: 23322918.

51. Sorensen M, Daneshvar B, Hansen M, Dragsted LO, Hertel O, Knudsen L, et al. Personal PM2.5 exposure and markers of oxidative stress in blood. Environ Health Perspect. 2003 Feb; 111(2):161-6. PMID: 12573899. Pubmed Central PMCID: PMC1241344.

52. Zhao J, Xie Y, Qian X, Jiang R, Song W. Acute effects of fine particles on cardiovascular system: differences between the spontaneously hypertensive rats and wistar kyoto rats. Toxicol Lett. 2010 Mar 1; 193(1):50-60. PMID: 20025942. doi: 10.1016/j.toxlet.2009.12.002

53. Wu S, Deng F, Wei H, Huang J, Wang H, Shima M, et al. Chemical constituents of ambient particulate air pollution and biomarkers of inflammation, coagulation and homocysteine in healthy adults: a prospective panel study. Part Fibre Toxicol. 2012; 9:49. PMID: 23231781. Pubmed Central PMCID: PMC3585865. doi: 10.1186/1743-8977-9-49

54. Schicker B, Kuhn M, Fehr R, Asmis LM, Karagiannidis C, Reinhart WH. Particulate matter inhalation during hay storing activity induces systemic inflammation and platelet aggregation. Eur J Appl Physiol. 2009 Mar; 105(5):771-8. PMID: 19125285. doi: 10.1007/s00421-008-0962-9

55. Pieters N, Plusquin M, Cox B, Kicinski M, Vangronsveld J, Nawrot TS. An epidemiological appraisal of the association between heart rate variability and particulate air pollution: a meta-analysis. Heart. 2012 Aug; 98(15):1127-35. PMID: 22628541. Pubmed Central PMCID: PMC3392690. doi: 10.1136/heartjnl2011-301505 